\title{
Light Pattern, Labirin Ruang Masif
}

\author{
I Wayan Sujana ${ }^{1}$, Tjok Istri Ratna Cora Sudharsana ${ }^{2}$ \\ ${ }^{1} J u r u s a n$ Seni Murni, Fakultas Seni Rupa dan Desain, Institut Seni Indonesia \\ ${ }^{2}$ Jurusan Desain Mode, Fakultas Seni Rupa dan Desain, Institut Seni Indonesia \\ Jalan Nusa Indah Denpasar, 80235, Indonesia \\ 1suklusujana@gmail.com
}

\begin{abstract}
Penelitian ini bertujuan untuk menemukan dan mempertunjukkan "intermingle art project Light Pattern, Labirin Ruang Masif" berbasis seni rupa pertunjukan untuk menjawab kurangnya seni rupa pertunjukan kontemporer yang berbasis riset. Permasalahan yang dirumuskan dalam penciptaan ini adalah Situasi dan keadaan psikologis seperti apa dari bentuk intermingle antara drawing on novel dengan seniman-seniman ? Gagasan atau konsep praksis seperti apa terekspresikan dari intermingle drawing on novel? Bagaimana bentuk presentasi intermingle art project ini ke ruang publik tertentu? Teori yang digunakan dalam penelitian ini adalah significant form, aesthetic relational serta teori presentasi, teori-teori tersebut sangat menunjang dalam penelitian. Pengumpulan data melalui observasi partisipatori, wawancara, dan studi kepustakaan. Model analisis interaktif digunakan dalam menyajikan data dan penyajian hasil analisis data disajukan secara informal dan formal. Hasil penelitian menunjukkan setiap seniman melahirkan sudut pandang yang berbeda sesuai dengan bidang seni yang ditekuni. Berbagai bentuk seni muncul: visual, verbal, sound, dan kenestetik seni kontemporer. Dipresentasikan dengan layer-layer ulang-alik senirupa-senipertunjukan.
\end{abstract}

Kata kunci: light pattern, seni rupa pertunjukan, intermingle

\section{Light Pattern, The Labyrinth Of Masive}

This study aims to find and demonstrate the "intermingle art project Light Pattern" based on fine art performances to answer the lack of contemporary research-based on performance art. The problem formulated in this creation is what kind of psychological situation and conditions of the intermingle form between drawing on novels and artists. The ideas or praxis concepts are expressed from intermingle drawing on novels. The form of presentation of this intermingle art project to certain public spaces. The theory used in this study is significant form, aesthetic relational and presentation theory, these theories are very supportive in the research. Data collection through participatory observation, interviews, and literature studies. An interactive analysis model is used in presenting data and presenting the results of the analysis informally and formally. The results of the study showed that each artist create a different perspective in accordance with the field of art in which he was engaged. Various forms of art emerge: visual, verbal, sound, and kinesthetic contemporary art. Presented with the shuttle layers in the form of art.

Keywords: light pattern, performing visual arts, intermingle.

Proses Review : 1 - 20 Agustus 2019, Dinyatakan Lolos: 22 Agustus 2019 


\section{PENDAHULUAN}

Menggali ladang seni seperti menggali belantara hutan sumber cipta seni, kejutan-kejutan sudut pandang dapat dipantau dan berhamburan didepan mata. Pemandangan berlapis-lapis hutan belantara semakin bermakna karena cara amatan sudah siap dengan pengetahuan sumber penciptaan seni, tahapan-tahapan pernciptaan, serta penghadiran karya seni. Seniman tinggal menentukan view pemandangan yang akan digali, kemudian disiapkan perangkat-perangkat metoda penciptaan untuk menggarapnya.

Novel salah satu berbagai jenis buku lainya penulis temukan ditengah hutan belantara sumber cipta seni. Buku novel sebuah benda (medium) yang didalamnya termaktub naskah seorang sastrawan yang dikemas penerbit seperti sebuah tubuh yang memiliki tampilan dan ruh. Setelah dibaca, isi novel terperangkap dalam ingatan pembaca, selanjutnya novel menjadi benda biasa lagi. Novel yang sudah terbaca ini menjadi phenomena menarik dilihat dari berbagai sudut pandang penulis. Buku novel tersebut pada galibnya menjadi ruang perangkap beberapa entitas seperti; entitas sastrawan, entitas grafikus, entitas penerbit, dan entitas pembaca. Entitas-entitas yang terperangkap dalam novel tersebut adalah simulakrum tanda yang mensejarah didera oleh waktu-kewaktu.

Seperti paparan diatas novel benda temuan memiliki kekasan sejarah dalam pembentukannya, hal-hal metaporik melekat semenjak awal, sekaligus penulis gunakan sebagai medium ekspresi penciptaan. Selanjutnya penulis sebut sebagai "drawing on novel", novel yang didalamnnya setiap lembar berisikan drawing disebelah kanan dan bayangan di lembar sebelah kiri. Fiksi satrawan yang terperangkap di buku novel dikawinkan dengan fiksi visual yang penulis buat, terjadi peristiwa interaksi tektual literasi-visual.

Drawing on novel di dalam buku novel menjadi inspiratif bagi sebagian masyarakat seniman. Pematung, arsitek, film maker, pelukis, desain fashion, perform, sastrawan, dan pemusik mempersepsi drawing on novel dengan bingkai masing-masing. Teman-teman seniman membuat kisah sendiri terhadap novel yang sudah di drawing tersebut, sebagian menelisik pola-pola drawing sebagian merasakan diksi sastra-visual sebagian ikut terlibat melarut di dalam novel. Seniman melakukan penghayatan meteri-partikel pada benda drawing on novel, muaranya adalah penghayatan ruang intermingle tubuh dan ruh.

Pertanyan-pertanyaan kemudian muncul, Situasi dan keadaan psikologis seperti apa terjadi pada seniman-seniman setelah beradu pandang dengan drawing on novel? Gagasan atau konsep praksis seperti apa terekspresikan dari intermingle drawing on novel? Sebelum melanjutkan pertanyaan berikutnya penulis sendiri menangkap tanda-tanda serta hasil respons teman-teman seniman, kemudian bertindak mengelaborasi icon-icon unik yang dihasilkan. Hal ini memunculkan pertanyaan berikutnya, bagaimana bentuk presentasi intermingle art project ini ke ruang publik tertentu?

Permasalahan-permasalahan yang muncul tersebut perlu dijawab sebagai akibat dari tujuan penelitian ini dilakukan, selain itu penelitian ini dapat memberi manfaat bagi keberlangsungan seni rupa pertunjukan dan menjawab sejauh mana seni rupa pertunjukan penting dalam seni kontemporer nasional dan internasional.

Pokus penelitian ini adalah hanya pada wilayah respos drawing on novel yang dilakukan teman-teman seniman kemudian respons penulis pada icon-icon unik tersebut. "IntermingleAart Project, Light Pattern Labirin Ruang Masif" menjadi tema metodologi penciptaan ini.

\section{METODE PENELITIAN}

Langkah-langkah penciptaan melalui dua zona, dapat di uraikan melalui tiga tahapan, secara kongkrit dapat dipertanggung jawabkan dari aspek keilmuan. "Intermingle Art Project, Light Pattern Labirin Ruang masif" adalah konsep yang penulis sebut sebagai zona pemikiran (partikel), merupakan zona diproduksi pemikiran-pemikiran atau gagasan-gagasan. Pandangan dan gagasan tentang "Intermingle Art Project, Light Pattern Labirin Ruang Masif" dapat menjawab atas pemikiran penciptaan elaborative. Novel temuan yang dijadikan medium ekspresi memantik seniman -seniman untuk melakukan tindakan penciptaan baru, menjadi model penciptaan yang membangun spirit kolektivitas dalam berkesenian. Zona ini mengartikulasi; 1. Seluruh pengalaman bawah sadar (unconscious); 2 . Wawasan; 3. ilmu pengetahuan, 4. alam, 5. serta Spiritualitas. Lima komponen tersebut berkelindan mengkuntruksi gagasan-gagasan, pada kesempatan ini gagasan "Light Pattern Labirin Ruang Masif”.

Zona kedua adalah perwujudan karya (materi), finalnya adalah penghadiran karya di site. Zona ini adalah kompleksitas metoda penciptaan dari aras gagasan, pengekspresian, dan muara akhir adalah presentasi. Secara sederhana dapat digambarkan tiga tahap metoda penciptaan: $\mathbf{1}$. M-making of contemporary art blueprint based on society (membuat cetak biru karya seni rupa pertunjukan kontemporer berbasis masyarakat); 2. A-accomplish singularity contemporary performing art based on society with deep spirituality (menyelesaikan karya seni rupa pertunjukan kontemporer berbasis masyarakat melalui spiritual yang mendalam); 3. L-longitude and latitude make transfer point of deep feeling throughout presentation (garis bujur/ horizontal dan garis lintang/pertikal membuat titik transfer rasa terdalam melalui presentasi). selanjutnya ketiga tahapan penciptaan penulis sebut sebagai konsep penciptaan MAL. 


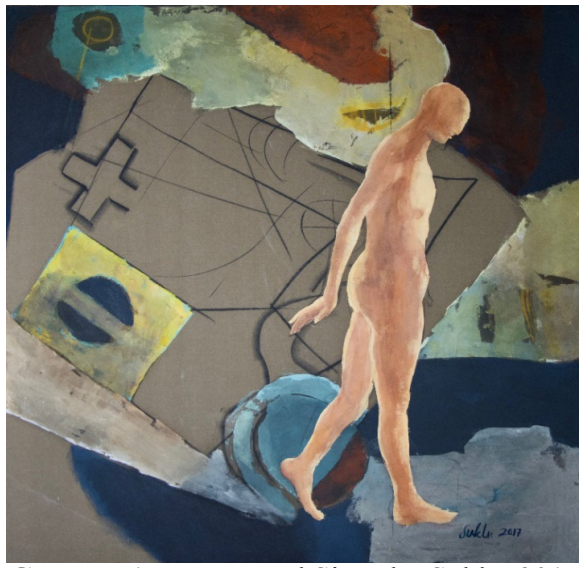

Gambar 1. Human and Signs by Suklu, 2017

(Dok: Sujana, 2017)

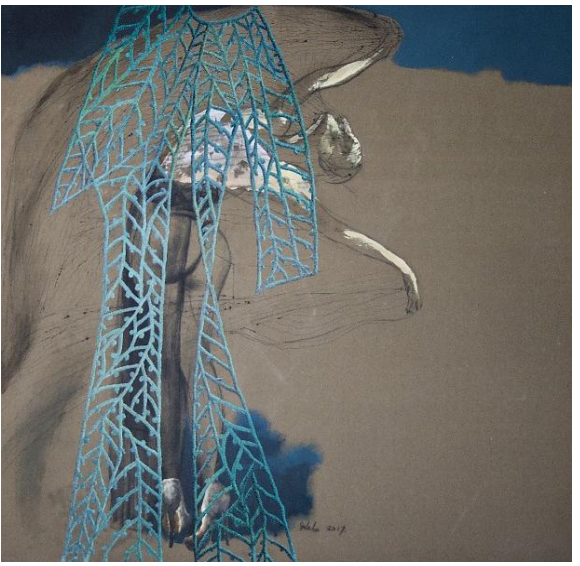

Gambar 2. The Dance behind the Green Cloak by Suklu, 2017

(Dok: Sujana, 2017)

kontemporer berbasis masyarakat). Pada tahap ini penulis menentukan dua aspek penting memformulasikan ide dan gagasan: Ide Pemantik, Buku novel ratusan buah dengan berbagai gnre sudah tuntas, bergambar ekspresif setiap lembarnya. Komunikasi intens dilakukan dengan seniman-seniman untuk menggagas art project, melalui konsep intermingle, kemudian artepak darwing on novel sebagai pemantik. Artepak novel menjadi perantara komunikasi yang sangat dalam dengan seniman-seniman. Berbagai keunikan cerita disetiap seniman yang dijumpai, sampai pada beberapa seniman yang bersiap terlibat. Perupa, pemahat, sastrawan, videomaker, filmmaker, arsitek, desainer, koreografer, dan composer berangkat dari drawing on novel sebagai pemantik menciptakan konsep garapan. Tahapan-tahapan komunikasi intens dengan seniman-seniman, penulis menetapkan art intermingle project ini sebuah proses filosofis yang dalam, menyamakan gelombang materi-partikel penuh misteri(setiap seniman menemukan pengalaman dan rasa unik). Penulis dan seniman-seniman menemukan perspektif baru dalam menguji metoda penciptaan dan menjangkarnya dengan judul ,"Light Pattern, Labirin Ruang Masif".

Keyword Conceptual:

$\begin{array}{ll}\text { DRAWING ON NOVEL } & \text { SOUND ARSITEKTUR } \\ \text { INTERTEKTUAL } & \text { VERBAL } \\ \text { MULTI MEDIA } & \text { KENESTETIK }\end{array}$

A-accomplish singularity contemporary performing art based on society with deep spirituality (menyelesaikan karya seni rupa pertunjukan kontemporer berbasis masyarakat melalui spiritual yang mendalam). Kata kunci konsep penciptaan seni yang sudah ditetapkan pada tahap ide pemantik (drawing on novel, intertekstual, multi media, sound, verbal, kenestetik, arsitektur,) menjadi tool praksis berikutnya. Pada tahap ini penulis menentukan tiga aspek penting memformulasikan proses penciptaan diurai kedalam art object (visual), perform(gerak), musik(sound), dan verbal(narasi). Tiga tahapan tersebut antara lain: 1. Concept Excavation; 2. Exploration; 3 Formation.

Concept Excavation. Tindakan penggalian kemungkinan-kemungkinan bentuk, elaborasi dari berbagai artepak

\section{MAL}

M-making of contemporary art blueprint based on society (membuat cetak biru karya seni rupa pertunjukan 


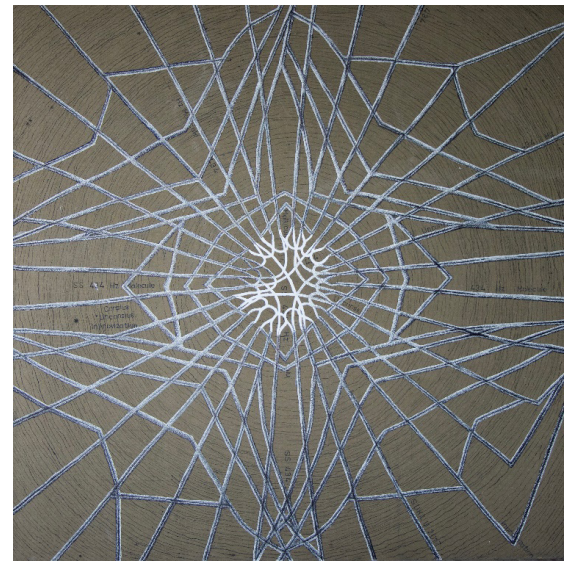

Gambar 3. HZ 343 by Suklu (Sumber: Sujana, 2017)

novel, pada proses ini masing-masing seniman melakukan respons terhadap drawing on novel yang sudah dipilih. Penulis melakukan tindakan balik merespons icon-icon unik yang dihasilkan partisivatif seniman, dengan tetap berpatokan pada keyword conceptual yang sudah ditetapkan. Exploration. Tindakan selanjutnya adalah melakukan percobaan-percobaan, menentukan pilihan-pilihan, kemudian diolah menjadi konsep-konsep yang mandiri. Konsep-konsep mandiri dengan berbagai keunikan estetik dan artistic dari berbagi semiotic adalah bagian cikal bakal seni rupa pertunjukan kontemporer. Formating. Pada tahap akhir pembentukan adalah final konsep bentuk visual-literasi-kenestetik-sound-site, komunikasi lebih kompleks diperlukan dengan melibatkan artist partisifatif, untuk mencari titik temu penggarapan secara keseluruhan. L-longitude and latitude make transfer point of deep feeling throughout presentation (garis bujur/horizontal dan garis lintang/pertikal membuat titik transfer rasa terdalam melalui presentasi). Site presentasi menjadi pertimbangan yang sangat berguna pada timbang bujur dan timbang lintang tempat pertunjukan. Art object menjadi bagian arsitektur dan atau mandiri di outdoor. sejak awal konsep dibangun rencana presentasi sudah menjadi bagian konsep pertunjukan. Sastra-sastra lama yang mengungkap prihal bujur-lintang dapat dibaca pada Penanggalan Bali (ala ayuning dewasa, baik-buruknya waktu), feng shui (keyakinan surga dan bumi hidup dalam harmoni) sampai sekarang masih menjadi rujukan implementasi dalam kehidupan sehari-hari. Ada dua hal menjadi kajian pada tahapan ini yaitu: Interior Space. Art object menjadi bagian keseluruhan konsep arsitektural, seni (verbal,visual,sound,kenestetik) ada di dalam bangunan arsitektur. Exterior Space. Substansi dari art object mandiri di luar arsitektur, seni (verbal,visual,sound,kenestetik) berada di luar bangunan arsitektur. Art object mandiri membentuk eksistensi dengan kosmologi art object lainnya.

\section{PEMBAHASAN}

\section{Lima pola lima lukisan}

Refleksi pola imagi dari lima seniman, penulis rekam melalui percakapan yang unik, kenapa karena penulis sep- erti mengintrograsi teman-teman seniman. Sumerjana dengan garis-garis simetrik-nonsimetrik patitur music, jubah rajutan benang aneka warna dari tangan Ratna Cora, bentuk-bentuk primitive patung padas dari tangan terampil Darmadi-Sukerta-Miasa, Stoneman dari tubuh seorang Dekgeh, dan natural heroic garis-garis arsitektural Supie.

Artepak pola berupa kode-kode tersebut menegasi persepsi, gambar mem-blas melalui retina mata tak kuasa memenjarakan kanal-kanal intuisi penulis. Tidak hanya pola gambar yang mengganggu, ideology si-empunya gambar hilir mudik mencari dan menohok kesadaran ideologis maupun kesadaran estetik. Imaji bekerja melakukan rancang bangun ide-ide. Penulis menentukan metodologis penciptan, dengan menentukan metoda-metoda tertentu menuju suasana puitik dari kekuatan puitik artepak pola. Metaporik bentuk sebagai penanda ideologi yang dihadirkan lima pola seniman, ditransformasi dalam tatanan metoda yang sudah diputuskan.

\section{"Manusia dan Tanda-tanda" 2017.}

Pola-pola garis-garis elaborasi Supie-Suklu yang meruang expressive-architectural dipinjam sebagai tanda berpadu dengan icon manusia telanjang sebagai mistifikasi kejujuran dan keluguan. Intertekstual bahasa rupa ini disadari dan ditimbang-timbang, untuk menjangkar makna filosofis yang digagas. Konsep gagasan ini muncul sepulang percakapan dengan performer DekGeh. Novel ditangan DekGeh telah menggoncang gagasan tentang 'stone body reflection', sepenggal ritus yang acap dilakoni DekGeh dalam merengkuh eksistensi dirinya. Sebuah narasi perform mengesplorasi tubuh sebagai subyek, yang terus berkulindan antara psikis dan sosio. Latar perjumpaan saya dengan sahabat DekGeh menjadi alasan dua icon disandingkan menjadi subyek komunikasi untuk membangun peng-kode-an, sehingga sensasi enigma manusia hidup dan terpenjara di dunia dapat dirasakan pada karya. Enigma hidup; terpenjara atau bebas? Sangat tergantung individu memaknai dan meng-interpretasi.

\section{“Tarian di Balik Jubah Hijau” 2017.}

Besar menjuntai menutup keseluruhan tubuh, imaji awal saat Ratna mengatakan kata kunci jubah sebagai gagasan konsep, entah jubah apa yang dimaksudkannya, kata kunci itu sudah saya dapatkan. Imaji saya menyisir dan mengerauk memori dan sekaligus intuisi. Persepsi terkait jubah muncul membayangi kesadaran simbolik saya, 'jubah' adalah selembar tekstil yang di drieving-melindungi tubuh dari desir dingin angin, 'jubah' adalah berhubungan dengan mitos tentang gelap dan penyamaran, 'jubah' adalah tirai dari jadah. Persepsi-persepsi tersebut menjadi titik berangkat saya memutuskan dan memilih kode-kode menjadi bahasa visual. Seseorang sedang menggerakkan tubuh layiknya dragon play sedang mengambang diantara tanah dan langit, kain melilit tubuh menjulur dan meliuk sampai keujung jari, meluruh mengikuti alur gravitasi bumi. Tubuhnya adalah ibu pertiwi sendiri. Tulang be- 


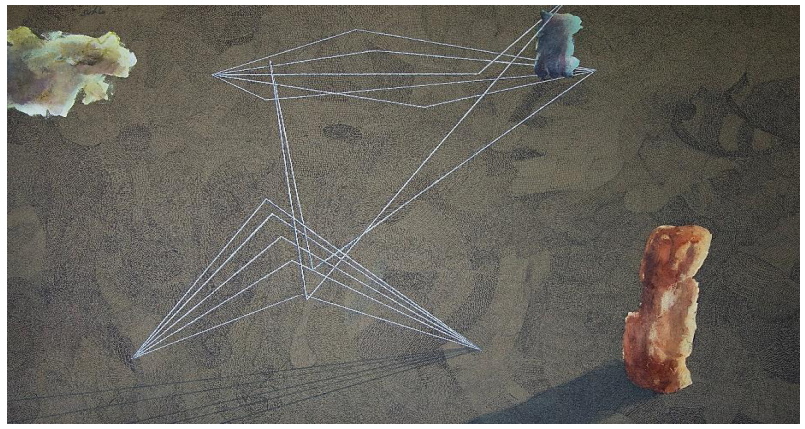

Gambar 4. Land of Wise Men by Suklu, 2017

(Dok: Sujana, 2017)

lulang daun berwarna hijau berbentuk jubah berdiri disamping depan, kedua icon itu melengkapi landscape tanah dgn orizon langit berwarna turkuis gelap. Sebuah peristiwa metaporik-visual yang saya bangun dengan pertimbangan prinsip-prinsip formalism ini, untuk membangkitkan memori-memori psikis manusia, ruang antara sadar-nirsadar mendapatkan percakapannya.

\section{“HZ 343" 2017.}

Patitur music terasa aneh, menyerupai garis-garis simetris bergerak lambat membentuk imaji tiga dimensi, hurufhuruf dan angka-angka berjejer seperti semut, disela-sela ruang pojok Sumerjana menambahkan tiga kata ' ', ' ', ' '. Saya menangkap pesan aneh sekaligus real, keseluruhan tanda pada gambar Sumerjana sangatlah replektif-argumentatif, sayang seperti dibuang kehadirat mitos laba-laba penciptaan alam semesta. Penciptaan dan getaran-getaran hanyalah jarring-jaring metodik yang sangat pratal, padanya intuisi kita sangkutkan untuk mendapatkan makna. Begitulah apa yang dibayangkan dari pola gambar patitur music Sumerjana, mewujud menjadi sangkar garisgaris melingkar dan meluas, hampir memenuhi bidang. Garis-garis melingkar diikuti oleh garis-garis melingkar yang lebih triadic-mistik. Sebuah pola matrik yang saling terhubung, masing-masing membawa signifikasi pada eksistensi entitas. Angka-angka itu terhubung dengan nafas bumi, planet, semesta...oh Hyang Widhi.

\section{"Tanah Manusia Bijak" 2017.}

Ratusan patung berserakan di halaman pelataran-pelataran Batu Belah Art Space, masing-masing menemukan kosmologinya. Patung-patung satupun tak serupa, seperti manusia. Karakter dan gestur berbeda-beda, masing-masing membawa tanda kelahiran. Beberapa dari mereka menarik perhatian saya, mereka seolah-olah bercakap tentang masa lalu(purba), mengabarkan tanah-tanah suci tempat manusia bijak menjelmakan literasi. Sakret-geometrik-animistik nyata seperti singasana, tempat melintaskan pandangan keseluruhan penjuru tanah. Icon salah satu patung dipilih dengan berbagai tetimbang, gelagat dan ekspresi ornament serta keniscayaan purba. Geometric-animistik dipadukan dengan elemen awan dan bayangan, keseluruhan tanda tersebut ditasbihkan untuk keseluruhan rasa puitik liris tentang tanah yang masih memancarkan karisma.

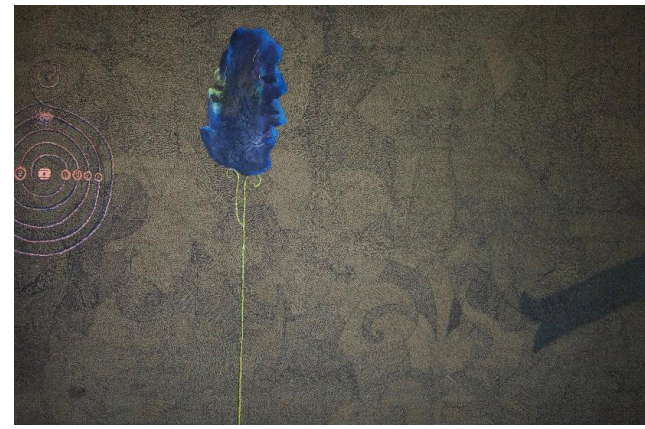

Gambar 5. Mystical, Shadow and Blue Statue by Suklu, 2017 (Dok: Sujana, 2017)

"mistik, bayangan dan patung biru" 2017.

Patung-patung batu padas eksis diantara bayangan-bayangan daun, amatan pada tanah, dan balutan tekstur angin, suasana tersebut membimbing pada suasana dejavu. Situasi tersebut berdampak pada gelombang psikis pengamat. Dampak pencapaian kontemplatif dalam keheningan yang ingin ditemukan dalam karya "mistik, bangan dan patung biru".

\section{SIMPULAN}

Hasil penelitian menunjukkan bahwa masing-masing seniman menciptakan perspektif yang berbeda sesuai dengan bidang seni dimana ia terlibat. Berbagai bentuk estetik muncul : seni kontemporer visual, verbal, suara dan kinestetik. Disajikan dengan gaya intermingle (bersahut-sahutan).

Menggambar pada novel menjadi inspirasi bagi beberapa seniman. Para pematung, arsitek,pembuat film, pelukis, perancang busana, pemain, penulis dan musisi mempersepsikan gambar pada novel dengan bingkai pemikiran masing-masing. Seniman membuat cerita mereka sendiri tentang novel yang telah digambar, beberapa diantaranya mengeksplorasi pola gambar-gambar pada novel, beberapa merasa bahwa diksi sastra-visual sebagian terlibat dalam pelarutan dalam novel. Seniman menghayati partikel pada novel yang sudah ditarik tujuannya adalah untuk menghargai ruang berbaurnya tubuh dan roh.

Refleksi pola imajiner dari lima seniman, penulis merekam melalui percakapan unik dengan menciptakan lima lukisan. "Human and Signs" hasil respons terhadap garisgaris arsitektur heroic alami oleh Supie serta Stoneman tubuh DekGeh, "The Dance behind the Green Cloak" hasil respons dari jubah rajutan Ratna Cora, " $H Z$ 343" respons terhadap garis-garis simetris-nonsimetris dari musik partitur Sumerjana, "Land of Wise Men" respons terhadap patung Nyoman Darmadi dan Made Miasa, dan "Mystical, Shadow and Blue Statue" adalah respons terhadap patung padas Ketut Sukerta. 


\section{DAFTAR RUJUKAN}

Hawkins, Alma.M. 1991. Moving from Within: A New Method for Dance Making. A Cappella Books (IL). English

Ratna Cora, Tjok Istri. 2011. "Wacana Fesyen Global dan Pakaian di Kosmopolitan Kuta”. disertasi Program Doktor. Program Studi Kajian Budaya. Program Pascasarjana Universitas Udayana. Denpasar

Widodo, Triyono. 1999. Seni Lukis Dasar. Malang: IKIP Malang 